\title{
Another case of underprovision of mitral valve repair surgery: Lessons from the Veterans Affairs health system
}

\author{
Anelechi C. Anyanwu, MD, and David H. Adams, MD \\ From the Department of Cardiovascular Surgery, Mount Sinai Medical Center, New York, NY. \\ Disclosures: The Icahn School of Medicine at Mount Sinai receives royalty payments from Edwards Lifesciences \\ and Medtronic for intellectual property related to Dr Adams' involvement in the development of 2 mitral valve \\ repair rings and 1 tricuspid valve repair ring. Dr Anyanwu has nothing to disclose with regard to commercial \\ support. \\ Received for publication Sept 20, 2017; accepted for publication Sept 20, 2017; available ahead of print Oct 31, \\ 2017. \\ Address for reprints: Anelechi C. Anyanwu, MD, Department of Cardiovascular Surgery, Mount Sinai Medical \\ Center, 1190 Fifth Ave, New York, NY 10029 (E-mail: anelechi.anyanwu@mountsinai.org). \\ J Thorac Cardiovasc Surg 2018;155:118-9 \\ $0022-5223 / \$ 36.00$ \\ Copyright (C) 2017 by The American Association for Thoracic Surgery \\ https://doi.org/10.1016/j.jtcvs.2017.09.098
}

The article in this issue of the Journal by Bakaeen and colleagues ${ }^{1}$ reports trends in the practice and outcomes of patients who underwent mitral valve surgery in the Veterans Affairs (VA) health system of the United States. Their observations confirm that there remains great disparity in care of patients with mitral valve disease and give indications that mitral valve surgery in the VA system may not be achieving key guideline-directed goals. For example, half the patients were in New York Heart Association functional class III or IV, and $15 \%$ had severe left ventricular dysfunction at time of surgery. These findings are contrary to current guidelines, which recommend earlier surgical intervention. The most disquieting observation, however, was a repair rate of $58 \%$ in patients with presumed degenerative disease. Although the repair rate improved with time, it was only $65 \%$ in 2013 (the final year of study), a time at which expert opinion and contemporary data suggest that repair rates should be in excess of $95 \%{ }^{2,3}$ Indeed several authors of the report of Bakaeen and colleagues ${ }^{1}$ are expert surgeons who have reported very high repair rates in their academic centers, which their groups were not able to replicate in affiliated VA hospitals. This dichotomy highlights the difference between real-world practice and reference center practice, and it suggests that mitral valve surgical expertise is not necessarily transferrable from a high-volume hospital to an affiliated low-volume hospital, even if an expert mitral surgeon is overseeing both systems. We have recently demonstrated the converse; low-volume surgeons in high-volume reference centers have higher valve repair rates than do other low-volume surgeons, ${ }^{4}$ suggesting an important center effect and also a probable Hawthorne effect, whereby low-volume surgeons benefit from being in the immediate vicinity of high-volume surgeons. Both experiences support the critical importance of consolidating center volume and expertise.

Although we have some concerns regarding the robustness of the data (it seems implausible, for

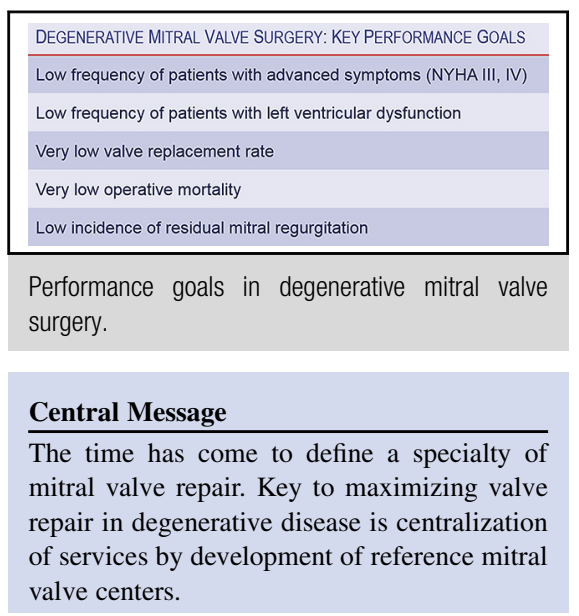

See Article page 105.

example, that a group of surgeons with a repair rate of $58 \%$ for degenerative disease would have a repair rate of $61 \%$ for rheumatic disease), the central question remains that of whether the veterans are best served by undergoing their mitral interventions within the current system. All the VA hospitals in this study were lowvolume mitral surgery centers (median of 7 cases per year, maximum of 29 cases per year), and the repair rate varied greatly. The issue arises of whether mitral surgery should be treated like transplantation and some other specialized services within the VA system, with patients being operated on either only in select regional VA hospitals with high repair rates or in the neighboring affiliated academic centers.

The VA system is not itself unique, and such disparities in provision of mitral valve surgery are well described in other health systems. ${ }^{5}$ The inconvenient truth remains that patients who undergo mitral valve surgery in low-volume mitral valve surgery centers (which currently includes all VA hospitals) are less likely to receive guideline-directed therapy (early surgery and durable repair of repairable valves) than are patients who go to high-volume repair centers. A solution often proposed is to train surgeons in low-volume centers to develop expertise in mitral valve repair. The report by Bakaeen and colleagues ${ }^{1}$ challenges such an approach, however, because even with well-trained surgical teams, the repair rate at the 
low-volume VA hospitals did not mirror that typically seen in affiliated academic hospitals. There is a center effect distinct from the surgeon effect. We agree with Gillinov and colleagues ${ }^{6}$ that the time has come to define a specialty of mitral valve repair and that the "who and where," in terms of surgeon and hospital performing the repair, must become a critical part of the decision-making algorithm. The solution to the lottery of mitral valve surgery, ${ }^{5}$ and the key to maximizing application of valve repair in degenerative disease, is the centralization of services and development of reference mitral valve centers. Otherwise, if the current systems remain, these periodic reports of underprovision and variation in mitral valve repair surgery will continue to be prevalent in our literature.

\section{References}

1. Bakaeen FG, Shroyer AL, Zenati MA, Badhwar V, Thourani VH Gammie JS, et al. Mitral valve surgery in the US Veterans Administration health system: 10-year outcomes and trends. J Thorac Cardiovasc Surg. 2018; 155:105-17.e5.

2. Gillinov AM, Mihaljevic T, Javadikasgari H, Suri RM, Mick SL, Navia JL, et al. Early results of robotically assisted mitral valve surgery: analysis of the first 1000 cases. J Thorac Cardiovasc Surg. 2018;155:82-91.e2.

3. Castillo JG, Anyanwu AC, Fuster V, Adams DH. A near 100\% repair rate for mitral valve prolapse is achievable in a reference center: implications for future guidelines. J Thorac Cardiovasc Surg. 2012;144:308-12.

4. Chikwe J, Toyoda N, Anyanwu AC, Itagaki S, Egorova NN, Boateng P, et al Relation of mitral valve surgery volume to repair rate, durability, and survival. J Am Coll Cardiol. April 24, 2017 [Epub ahead of print].

5. Anyanwu AC, Bridgewater B, Adams DH. The lottery of mitral valve repair surgery. Heart. 2010;96:1964-7.

6. Gillinov M, Mick S, Suri RM. The specialty of mitral valve repair. J Am Coll Cardiol. April 24, 2017 [Epub ahead of print]. 